\title{
Pemanfaatan Limbah Kain Perca Sebagai Alternatif Peluang Usaha
}

\author{
Rani Septiawati $^{1}$, Aci Murhad ${ }^{2}$, Dina Dinata ${ }^{3}$, Reni Anggainy ${ }^{4}$, Winda Sari ${ }^{5}$, Febrianty ${ }^{6}$ \\ Politeknik Palcomtech
}

Korespondensi: febrianty@palcomtech.ac.id

Diserahkan: 25 Juli 2018, Direvisi: 5 Agustus 2018, Diterima: 18 Agustus 2018

\begin{abstract}
Abstrak
Kegiatan Program kreativitas mahasiswa Kewirausahaan (PKM-K) dengan nama "Bakar Kaca" yaitu bantal lukis karikatur kain perca ini ber tujuan untuk: 1) memanfaatkan limbah kain perca di lingkungan masyarakat, 2) mengasah kreativitas yang bernilai jual dikalangan mahasiswa serta masyarakat luas, 3) membuka peluang usaha dalam upaya meningkatkan kesejahteraan masyarakat dan 4) melatih jiwa kewirausahaan mahasiswa. Identifikasi dan pemecahan masalah pada kegiatan ini menggunakan metode Strength, Weak, Opportunity dan Threat. Pelaksanaan kegiatan dibagi dalam 2 (dua) tahapan yaitudesain dan pengerjaan. Kegiatan ini sangat bagus untuk peluang usaha mahasiswa, karena itu dukunga untuk keberlangsungan usaha sangat diperlukan, mengingat adanya potensi pengembangan usaha yang cukup besar berdasarkan hasil penjualan dan permintaan/minat konsumen.
\end{abstract}

Kata Kunci : PKM-K, Bakar Kaca, Peluang Usaha, Kain Perca

\begin{abstract}
The activities of the Entrepreneurship student creativity program (PKM-K) with the name "Bakar Kaca" are patchwork caricature painting cushions with the aim of: 1) utilizing patchwork waste in the community, 2) honing selling value among students and the wider community, 3) open business opportunities in an effort to improve community welfare and 4) train students' entrepreneurial spirit. Identification and problem solving in this activity uses Strength, Weak, Opportunity and Threat methods. The activities are divided into 2 (two) stages of design and workmanship. This activity is very good for student business opportunities, therefore support for business sustainability is very necessary, given the potential for large business development based on sales results and consumer demand / interest.
\end{abstract}

Keywords: PKM-K, Glass Burn, Business Opportunities, Patchwork

\section{A. PENDAHULUAN}

\section{Latar Belakang}

Limbah kain perca merupakan kain sisa potongan yang sudah tidak terpakai namun dapat dimanfaatkan. Para penjahit biasanya membuang sisa kain perca karena mereka kebanyakan tidak mengetahui dan merasa repot untuk memanfaatkan kain perca yang bernilai jual. Tim Pelaksana PKM-K mencoba memanfaatkan limbah kain perca sebagai alternatif peluang usaha, dengan cara mendaur ulang limbah kain perca menjadi produk yang bernilai jual yaitu dengan mengubah limbah kain perca menjadi bantal lukis karikatur.

Kurangnya pemanfaatan limbah kain perca membuat Tim Pelaksana PKM-K berfikir dengan menggunakan limbah kain perca sebagai bahan utama usaha akan memperoleh keuntungan dan menambah nilai ekonomis barang. Peluang usaha bantal lukis karikatur kain perca juga menjadikan tambahan penghasilan serta melatih jiwa kewirausahaan mahasiswa dan masyarakat luas. Selain itu, terbatasnya kreativitas yang bernilai jual semakin membuat tim semangat dalam mengolah limbah kain perca tersebut. Tim Pelaksana PKM-K berharap dengan memanfaatkan limbah kain perca sebagai bahan utama pembuatan bantal lukis, mampu menarik perhatian konsumen dan 
menjadikan kerajinan tangan kain perca ini menjadi keluaran yang unik dan variatif dari sekian banyak jenis kerajinan tangan.

\section{Mitra Pengusaha}

Untuk memberi panduan serta melatih para mahasiswa peserta PKM-K bermitra seorang pengusaha kain perca, yaitu ibu Irma. Beliau adalah pengusaha produk bantal lukis yang awalnya tidak dikenal tetapi mampu mengeksplor produknya menjadi produk hingga beberapa negara. Selain itu, beliau juga mempekerjakan para warga disabilitas untuk dalam meningkatkan usahanya, karena beliau juga berkebutuhan khusus (polio)

Kisah pengusaha tersebut secara tidak langsung memberi Tim Pelaksana PKM-K ide inspiratif yang membuat Tim Pelaksana PKM-K semakin semangat menjalani usaha bantal lukis karikatur dengan memanfaatkan limbah kain perca adapun yang membedakan usaha mereka dan usaha yang dibuat yaitu tim mencoba mengkolaborasikan limbah kain perca dengan ilmu melukis karikatur yang masuk kedesain aplikasi photoshop yang Tim Pelaksana PKM-K pelajari di Politeknik Palcomtec. Produk bantal lukis banyak digemari anak muda karena dapat digunakan sebagai hadiah ulang tahun, souvenir, dan koleksi pribadi. Bantal lukis karikatur tidak hanya menjadi produk yang mempunyai nilai seni tinggi tetapi juga sebagai produk yang kekinian dengan bermacam-macam karikatur. Tim Pelaksana PKM-K berharap bisa menjalani bisnis dengan sukses.

\section{B. TINJAUAN PUSTAKA}

PKM adalah singkatan dari Program Kreativitas Mahasiswayang diselenggarakan oleh Dikti kepada mahasiswa untuk menunjukkan kreativitasnya. PKM merupakan salah satu bentuk upaya yang dilakukan Direktorat Penelitian dan Pengabdian kepada Masyarakat (DP2M), Ditjen Dikti dalam meningkatkan kualitas peserta didik (mahasiswa) di perguruan tinggi agar kelak dapat menjadi anggota masyarakat yang memiliki kemampuan akademis dan atau profesional yang dapat menerapkan, mengembangkan dan meyebarluaskan ilmu pengetahuan, teknologi dan atau kesenian serta memperkaya budaya nasional dalam rangka mempersiapkan diri menjadi pemimpin yang cendekiawan, wirausahawan serta berjiwa mandiri dan arif, mahasiswa diberi peluang untuk mengimplementasikan kemampuan, keahlian, sikap tanggung jawab, membangun kerjasama tim maupun mengembangkan kemandirian melalui kegiatan yang kreatif dalam bidang ilmu yang ditekuni.

Hal ini menunjukkan minat dan perhatian serius dari pemerintah serta lembaga pendidikan untuk menstimulas minat berwirausaha pada mahasiswa (Lestari, R. B., \& Wijaya, T. (2012)

Jenis PKM yang diselenggarakan oleh DP2M ada 6 (enam) jenis dan salah satunya adalah PKM-K, yang merupakan wadah bagi mahasiswa untuk mengembangkan kegiatan wirausaha dengan stimulus dana dari DP2M. Diharapkan, kegiatan ini bisa menumbuhkan jiwa wirausaha kepada mahasiswa yang nantinya akan menularkan kepada lingkungan sekitar dan bisa menumbuhkan kegiatan usaha alternatif untuk menyerap tenaga kerja dan menghasilkan pemasukan. Mahasiswa penerima dana PKM-K diharapkan mampu menjadi agen pemberdayaan lingkungan sekitar (Purwanto, N., \& Rofiah, C. (2017) serta menjadi wirausaha yang unggul agar tidak menggantungkan kerja pada orang lain serta menjadi salah satu panutan yangt dapat mendorong budaya berwirausaha ( Andika, M., \& Madjid, I, 2012) 


\section{METODE}

\section{Pelatihan Desain}

Dalam mendesain, tim pelaksana PKM-K menggunakan kreativitas yang dimiliki dan tim juga mengambil referensi dari media internet sebagai acuan dalam mendesain sarung dari bantal lukis karikatur kain perca, agar mendapatkan hasil desain yang membuat konsumen tertarik untuk membeli produk bantal lukis karikatur yang dihasilkan. Berikut contoh desain yang digunakan tim PKM-K :

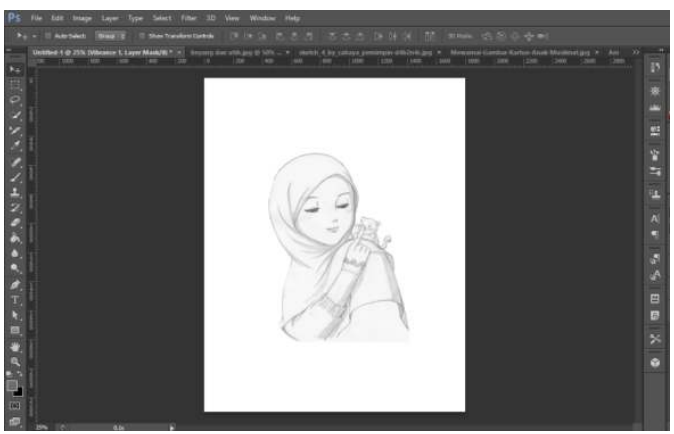

Gambar 1 Contoh Desain Lukis

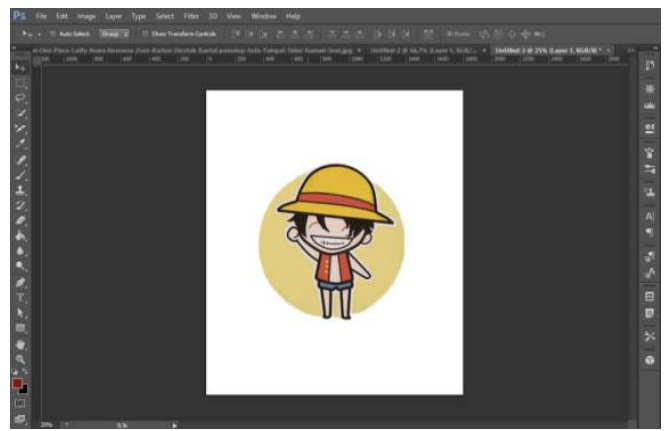

Gambar 2 Contoh Desain Karikatur

\section{Proses Pengerjaan}

Tahapan dalam pengerjaan bantal lukis kain perca adalah:

\section{a. Teknik Perancangan}

Dalam tahap ini akan dilakukan perancangan sesuai dengan barang yang akan diproduksi, yaitu seperti pembuatan pola dan model barang yang akan diproduksi.

b. Teknik Pemotongan Pola dan Model

Pada tahap ini untuk memotong kain yaitu masing masing 2 (dua) lembar kain polos yang telah di potong berukuran $40 \mathrm{~cm} \times 40 \mathrm{~cm}$, dan 2 (dua) lembar kain perca batik berukuran $40 \mathrm{~cm} \mathrm{X} 10 \mathrm{~cm}$.

\section{c. Teknik Desain Karikatur}

Dalam tahap ini yang pertama dilakukan yaitu mendesain karikatur yang telah dipesan oleh konsumen pada aplikasi photoshop dikomputer. Selanjutnya hasil desain dicetak melalui mesin printer.Setelah itu, hasil cetakan dijiplak menggunakan kertas karbon pada kain.Desain karikatur yang telah selesai, dicat menggunkan cat acrylic dan tunggu sampai cat mengering sebelum ke tahap selanjutnya.

\section{d. Teknik Pengemasan}

Bantal yang telah jadi dikemas dalam plastik kemasan dan rekatkan ujungnya menggunakan selotip. Selanjutnya kemasan akan dibuat semenarik mungkin.

\section{e. Teknik Pemasaran}

Teknik pemasaran PKM-K mempromosikan produk tersebut melalui jejaring sosial, karena kebanyaakan masyarakat saat ini menggunakan jejaring sosial dalam hal apapun, termasuk jual beli. Dengan demikian akan sangat menguntungkan apabila Tim Pelaksana PKM-K melakukan promosi melalui jejaring sosial seperti, Instagram, facebook, dan situs jejaring sosial lainnya.

\section{HASIL DAN PEMBAHASAN}

Kegiatan yang dilakukan tim pelaksana selama 2 (dua) bulan, menghasilkan produk yang bernilai jual bagus. Hal ini sesuai dengan target yang diharapkan dari kegiatan ini yaitu: 
1. Dapat menghasilkan suatu produk unik yang bernilai jual

Setelah mampu memproduksi bantal yang layak jual, tim PKM-K juga mampu menjual produk "Bakar Kaca" sebanyak 39 buah dengan rincian dengan ukuran besar $35 \times 35 \mathrm{~cm}$ sebanyak 29 buah bantal dan ukuran kecil $40 \times 20 \mathrm{~cm}$ sebanyak 10 buah bantal. Sisa bantal saat ini masih dalam proses pengerjaan dan masih berlangsung proses promosi dan penjualan, serta penerimaan pesanan.
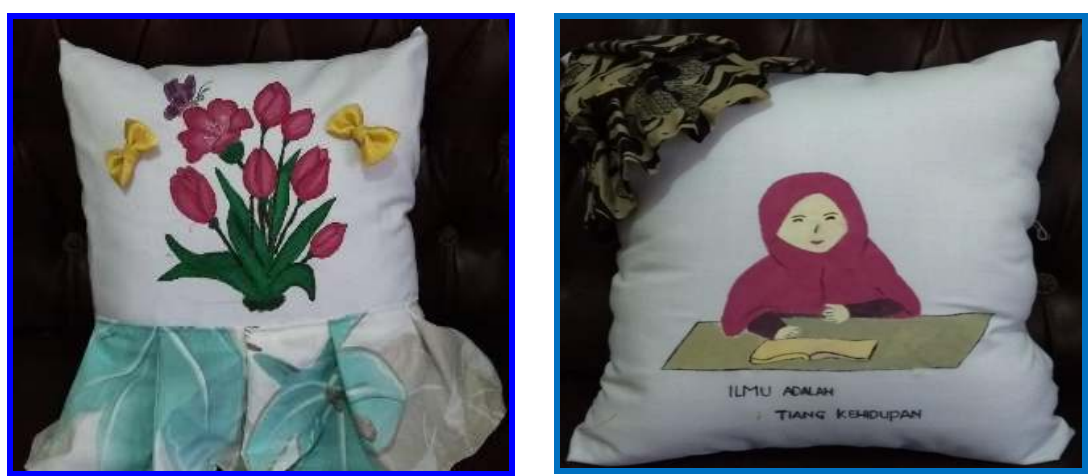

Gambar 3. Beberapa Contoh Bantal Bakar Kaca

Keuikan "Bakar Kaca" selain pada desain gambarnya, juga pada quotes (kata-kata mutiara) di bantal lukis karikatur kain perca, quotes tim lebih dominan kepada kata-kata motivasi yang bersifat Islami. Rencana pengembangan usaha ke depan, Tim Pelaksana PKM-K ingin memperkuat ciri khas produk yang dihasilkan disamping lukisan karikatur juga dengan menyajikan quotes Islami di produk bantal.

Untuk memudahkan identitas serta sebagai ciri khas produk, tim pelaksana PKM$\mathrm{K}$ juga telah membuat logo merek usaha yang berasal dari ide tim dan mendesainnya menggunakan corel drawdan setelah dilakukan mesin pencarian google tidak ditemukan merek yang sama atau gambar merek yang sama. Unsur warna utama logo merek usaha adalah depth yellow dan gold.

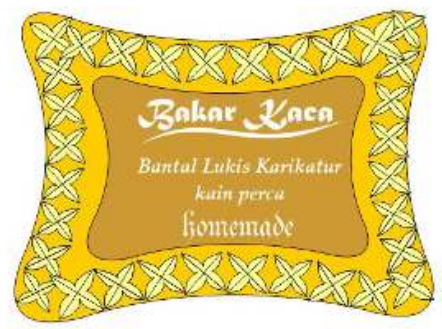

Gambar 4. Logo Merek Produk Usaha Tim Pelaksana PKM-K

\section{Inspirasi Bagi Mahasiswa Lain}

Kegiatan yang dilakukan oleh tim PKM-K ini, selain sebagai usaha alternatif bagi mahasiswa, diharapkan juga bisa menginspirasi mahasiswa lain untuk melakukan kegiatan ekonomi kreatif. Tim Pelaksana PKM-K mampu menerapkan keahlian dibidang teknologi dan seni denganmenggunakan Corel Draw dan melukisnya di atas kain drill. 

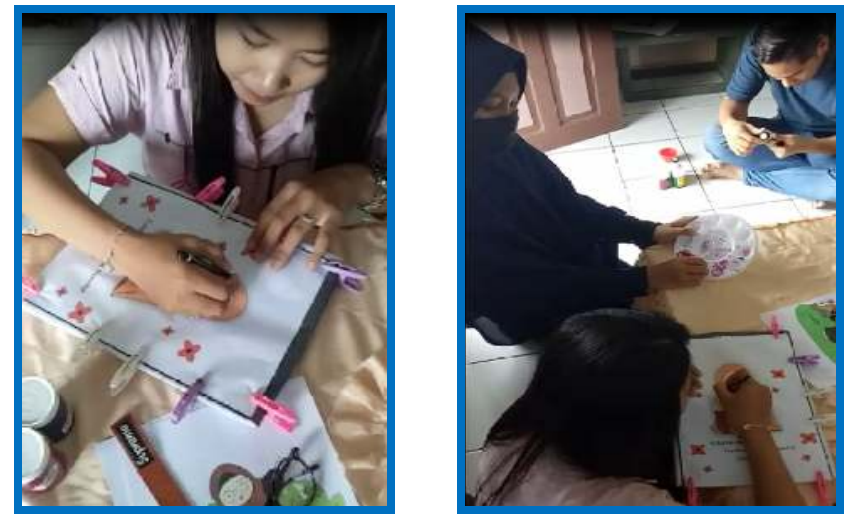

Gambar 3. Beberapa Contoh Bantal Bakar Kaca

Tim Pelaksana PKM-K telah dapat memanfaatkan limbah buangan kain perca dari beberapa penjahit di sekitar lingkungan rumah menjadi bahan dari bakar kaca yang dibentuk untuk aksesoris bantal dan sekaligus bantal.
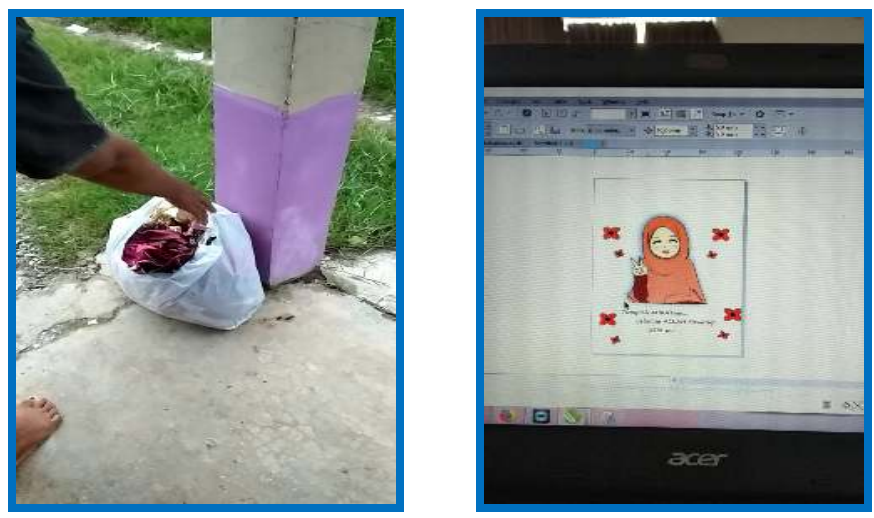

Gambar 6: Limbah Kain dan desain Corel Draw

\section{Menghasilkan kreativitas dan melatih jiwa kewirausahaan mahasiswa}

Pada kegiatan ini, tim pelaksana PKM-K juga membuat katalog produk untuk mempromosikan produk yang dihasilkan menggunakan ide kreatif tim. Katalog produk yang dibuat merupakan album atau kumpulan dari desain-desain bantal yang sudah dihasilkan, sehingga konsumen/calon konsumen dapat memilih desain dan pesanan desain yang diinginkan.
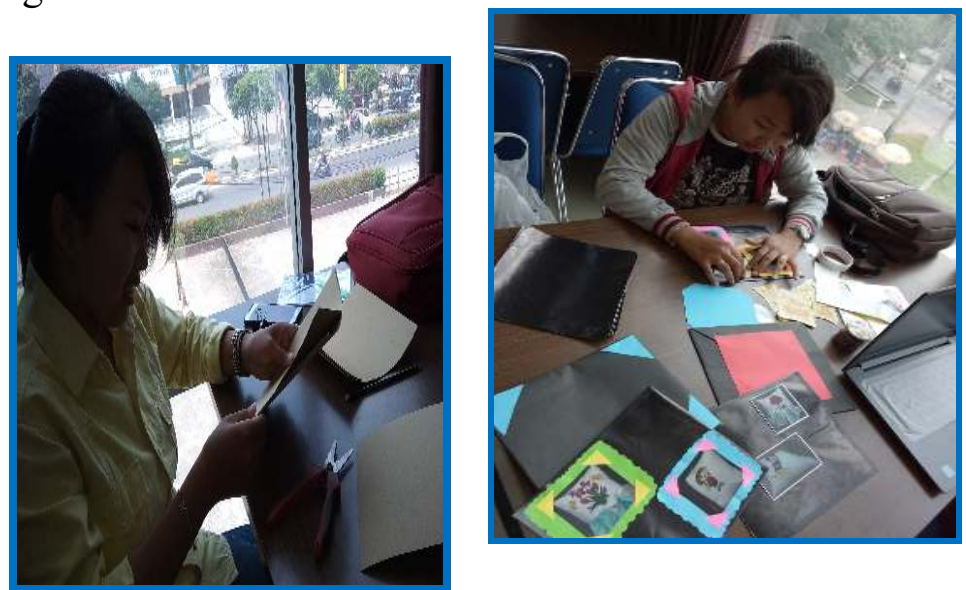

Gambar 9. Pembuatan Katalog Produk Menggunakan Kertas Karton 
Tim pelaksana PKM-K juga membuat pilihan kemasan/bungkus bantal jika bantal akan dijadikan kado atau hadiah. Kemasan ini bagi konsumen yang berminat dan memerlukan pembungkus bagi bantal Bakar Kaca yang telah dibelinya dimana harga jual pembungkus hanya $\mathrm{Rp} 4.000,-$-Rp 6.000,-. Pembungkus Bakar Kaca ini pun memanfaatkan sisa kain perca sebagai aksesoris.
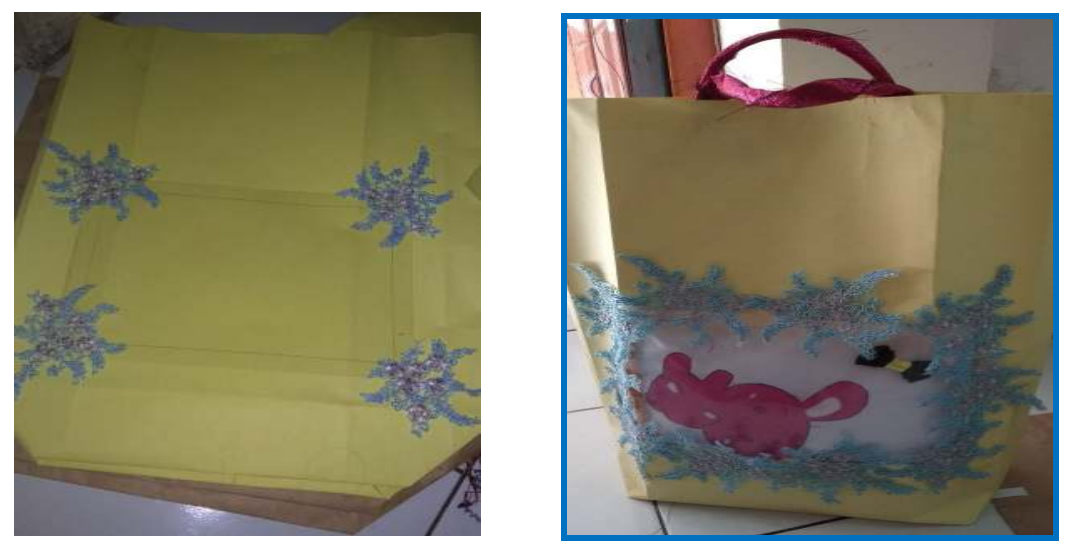

Gambar 10.Contoh Kantong Kemasan Bakar Kaca

Tim Pelaksana PKM-K membuat dan mengaktifkan beberapa akun di sosial media untuk promosi dan pemasaran produk antara lain :

1. olx (dengan alamat https://m.olx.co.id/iklan/bantal-lukis-kain-perca-macam2-motifIDvzTWl.html)

2. Instagram/IG(https://www.instagram.com/p/B1A5Su117wc/?utm_source=ig_share_sh eet\&igshid=fv7zrtksp7qt)

3. Akun facebook (dengan alamat https://www.facebook.com/bakar.kaca.716),

4. Akun tokopedia (https://m.tokopedia.com/bantalkarikatur) (baru terdaftar belum ada transaksi)

5. Grup WhatsApp (WA) Bakar Kaca
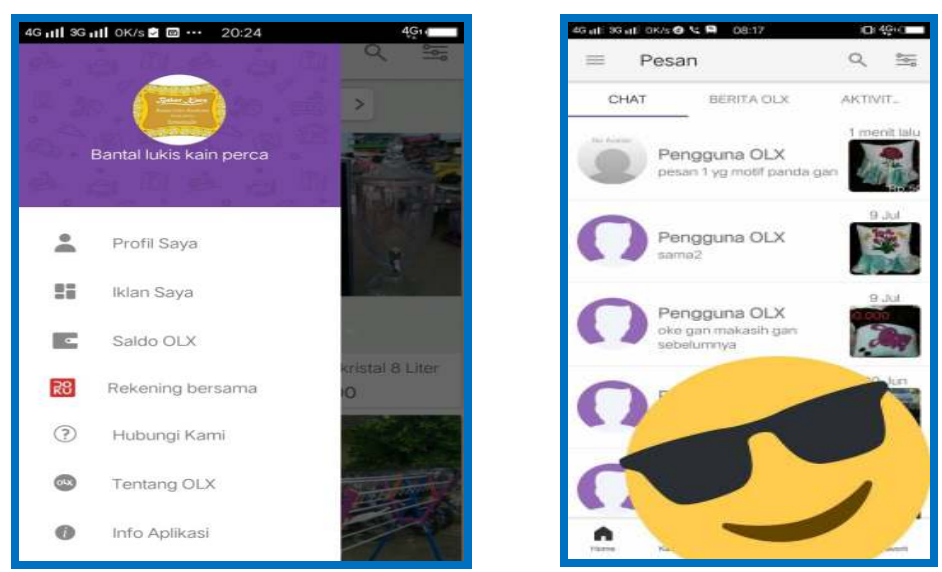

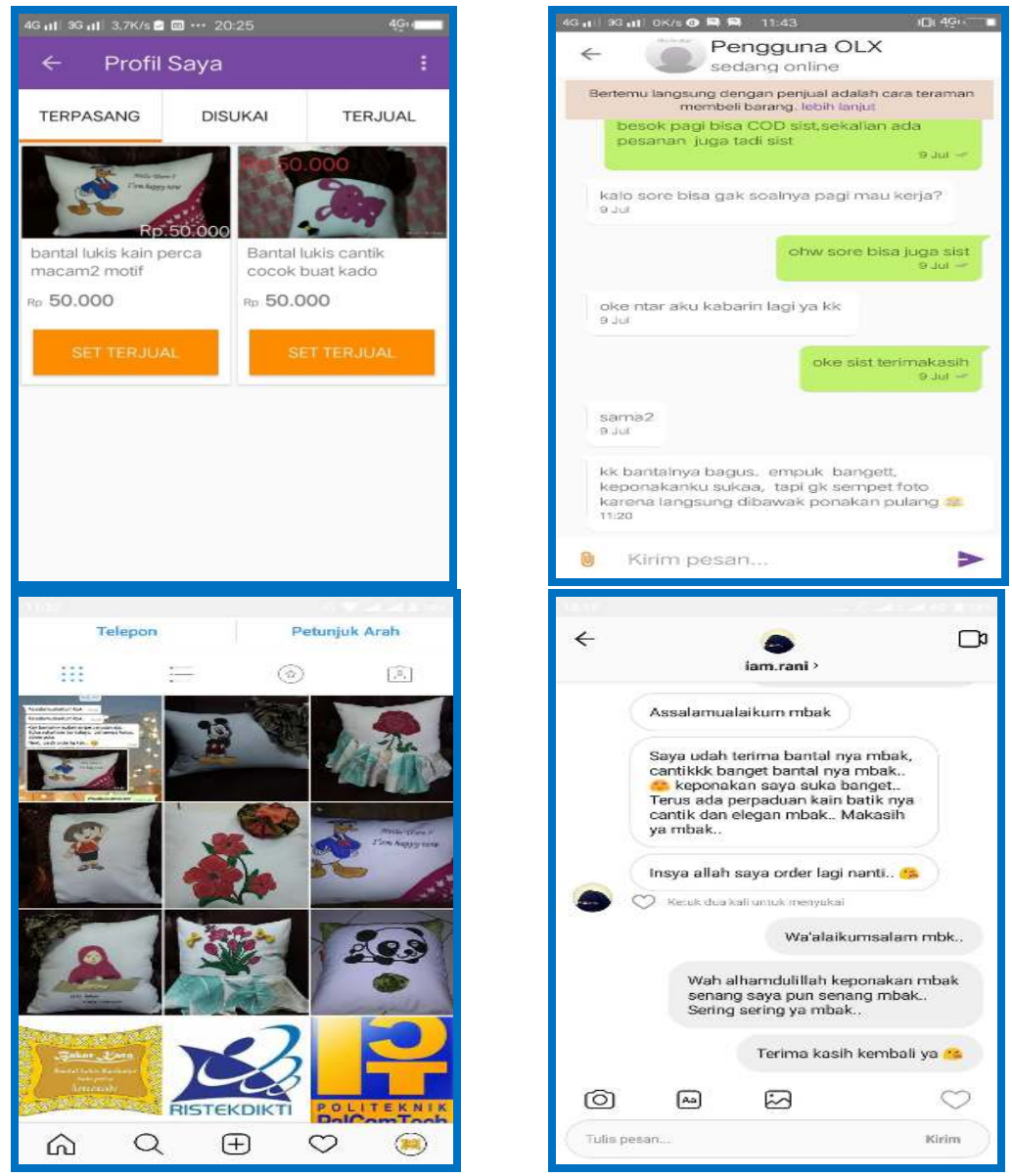

Gambar 11. Tampilan Akun dan Testimoni konsumen Bakar Kaca di OLX

Tim pelaksana juga melakukan rencana pengembangan desain karikatur lukis foto wajah dan pembuatan pilihan Ikonik Palembang). Masukan konsumen ini menjadi pertimbangan bagi Tim Pelaksana PKM-K karena bantal karikatur lukis foto wajah di pasaran belum banyak, yang tersedia banyak di pasaran adalah bantal print foto wajah. Berikut ini adalah tampilan salah satu permintaan konsumen untuk lukis foto wajah:
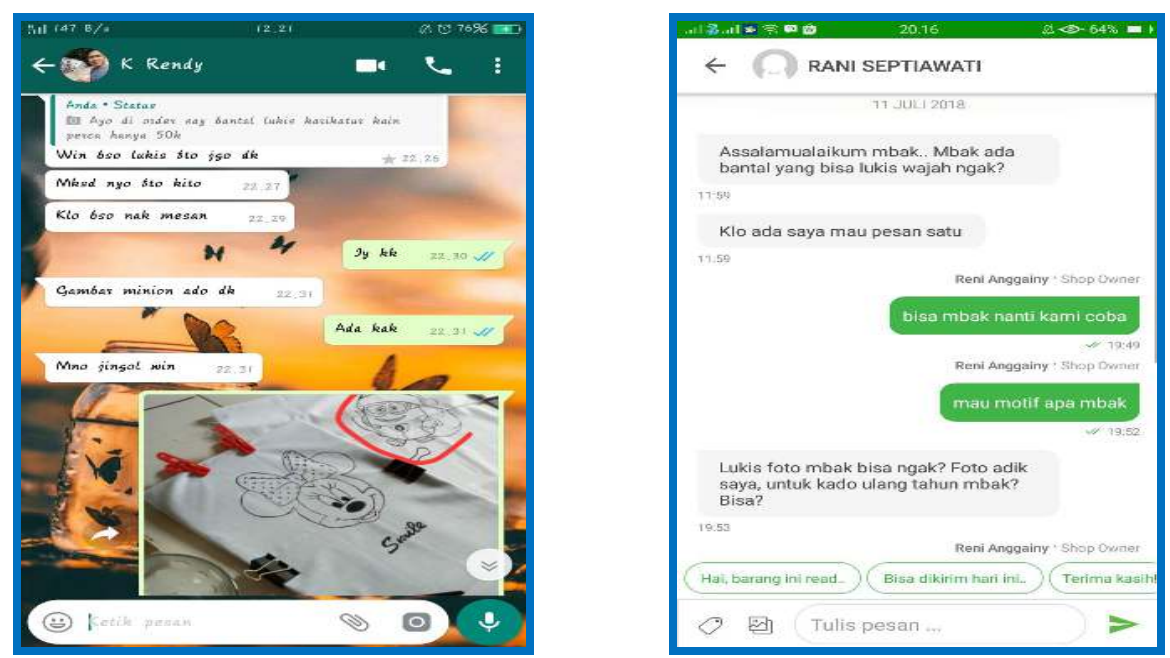

Gambar 16. Tampilan Permintaan Konsumen di Whats App dan di Tokopedia 
Masukan konsumen ini berarti bagi usaha Tim Pelaksana PKM-K karena tim anggap sebagai peluang pengembangan usaha dan menangkap kesempatan dari penyelenggaraan peristiwa penting seperti Asian Games di Kota Palembang.

\section{Memberikan pendapatan tambahan kepada mahasiswa}

Tim PKM-K Bakar Kaca optimis bahwa usaha Bakar Kaca akan tetap memiliki keuntungan di masa yang akan datang. Berdasarkan Laporan Laba/Rugi Usaha didapatkan realisasi sampai dengan per tanggal 31 Agustus 2018 usaha Bakar Kaca memperoleh keuntungan sebesar Rp. 6.380.000.00.

\section{E. PENUTUP}

Kegiatan PKM-K yang telah dilakukan oleh tim telah menunjukkan hasil hasil yang baik. Tim telah mampu memproduksi dan menjual produk "Bakar Kaca" dengan kreasi yang unik. Dengan berakhirnya kegiatan PKM-K ini, bukan berarti berakhir juga kegiatan produksi dan pemasaran produk "Bakar Kaca". Namun aspek keberlanjutan usaha juga perlu dipikirkan. Kegiatan produksi dan pemasaran Bakar Kaca tetap menjadi usaha yang menjanjikan pendapatan kepada mahasiswa dan terdapat potensi pengembangan usaha yang cukup besar berdasarkan hasil penjualan dan permintaan/minat konsumen. Keberlanjutan program bakar kacajuga mampu mendukung beberapa aspek kehidupan, seperti: aspek ekonomi, aspek lingkungan, dan aspek sosial. Aspek ekomoni yang dimaksud adalah hal yang dominan dalam PKM-K Bakar Kaca. Aspek lingkungan dari Program PKM-K Bakar Kaca adalah dimanfaatkannya limbah kain perca di sekitar lingkungan rumah Tim Pelaksana PKM$\mathrm{K}$ yang biasanya dibuang atau dibakar begitu saja oleh para penjahit. Sedangkan aspek sosial yang ditimbulkan dari Program PKM-K Bakar Kaca ini adalah dapat semangat kepada rekan-rekan mahasiswa untuk menciptakan peluang usaha yang secara langsung sehingga dapat mengurangi pengangguran.

\section{DAFTAR PUSTAKA}

Andika, M., \& Madjid, I. (2012). Analisis Pengaruh Sikap, Norma Subyektif dan Efikasi Diri Terhadap Intensi Berwirausaha Pada mahasiswa Fakultas Ekonomi Universitas Syiah Kuala. In Eco-Entrepreneurship Seminar \& Call for Paper" Improving Performance by Improving Environment (pp. 190-196)

https://eprints.uns.ac.id/26124/1/I0512003 $001027 \%$ E2\%80\%9CBAKAR ROMAH $\%$ E2\%80\%9D\%2C BANTAL LUKIS KA.pdf

(Diakses pada tanggal 12 november 2017 )

https://indonesiaproud.wordpress.com/2011/06/24/irma-suryati-angkat-martabatpenyandang-cacat-lewat-kain-perca/

( Diakses pada tanggal 15 november 2017 )

Purwanto, N., \& Rofiah, C. (2017). Pemberdayaan Usaha Ekonomi Produktif Bagi Masyarakat Di Kecamatan Ploso Kabupaten Jombang. Comvice: Journal Of Community Service, 1(1), 29-32.

Lestari, R. B., \& Wijaya, T. (2012). Pengaruh Pendidikan Kewirausahaan Terhadap Minat Berwirausaha Mahasiswa di STIE MDP, STMIK MDP, dan STIE MUSI. In Forum Bisnis Dan Kewirausahaan Jurnal Ilmiah STIE MDP (Vol. 1, No. 2, pp. 112-119). STIE MDP. 